\title{
Simulated Performance of Packed Bed Solar Energy Storage System having Storage Material Elements of Large Size - Part II
}

\author{
Ranjit Singh ${ }^{*}$, R.P. Saini ${ }^{2}$ and J.S. Saini ${ }^{3}$ \\ ${ }^{I}$ Department of Mechanical Engineering, Beant College of Engineering and Technology, Gurdaspur, Punjab, 143521, \\ India \\ ${ }^{2}$ Alternate Hydro Energy Centre, ${ }^{3}$ Department of Mechanical and Industrial Engineering, Indian Institute of Technology \\ Roorkee, Roorkee, Uttarakhand, 247667, India
}

\begin{abstract}
In the present paper an attempt has been made to report simulated performance of a packed bed solar energy storage system. Performance of the system having large size storgae material elements has been evaluated as a function of system and operating parameters. In the present part of this paper, system performance w.r.t. temperature distribution in the bed, thermal energy stored and available energy stored in the bed have been reported and discussed. It is observed that the system parameters play a predominant role to influence heat transfer characteristics of packed bed solar energy storage system.
\end{abstract}

Keywords: Packed bed, solar air heater, thermal energy storage.

\section{INTRODUCTION}

Intermittent nature of solar energy storage is the key issue to make this renewable energy source more reliable. Packed bed system is generally used for storing heat energy in air based solar energy system. Energy stored in the packed bed may be useful to have uninterrupted supply of energy in the absence of solar radiation and also to fulfill the peak load energy demands even in the presence of solar radiation.

As reported in Part-I of this paper, it is revealed from literature that the system design must be based on the methods to reduce pressure drop in the bed in order to enhance the effective use of solar energy system. Sagara and Nakahara [1] reported that large size material elements can be used for reducing pressure drop through the bed. Singh $e t$ al. [2] reported an extensive experimental study to analyze effect of shape of large sized material elements and void fraction of the bed under set of operating conditions. In order to predict the performance of packed bed system Nusselt number and friction factor correlations as a function of system and operating parameters have been reported by Singh et al. [2].

With the help of mathematical simulation reported in Part-I of this paper, system performance has been reported in the present part w.r.t. temperature distribution in the bed, thermal energy stored and available energy stored in the bed. It has been observed that the system parameters play a predominant role to influence heat transfer characteristics of packed bed solar energy storage system.

*Address correspondence to this author at the Department of Mechanical Engineering, Beant College of Engineering and Technology, Gurdaspur, Punjab, 143521, India; Tel: +91-1874-221464,

E-mail: rsolar70@yahoo.co.in

\section{RESULTS AND DISCUSSION}

The results obtained from the mathematical simulation w.r.t. temperature distribution in the bed, thermal energy stored and available energy stored in the bed are reported and discussed in the following sub-sections.

\subsection{Temperature Distribution in the Bed}

An average temperature of each bed element during charging of bed in a given time interval has been obtained with the help of mathematical simulation. Fig. (1) shows

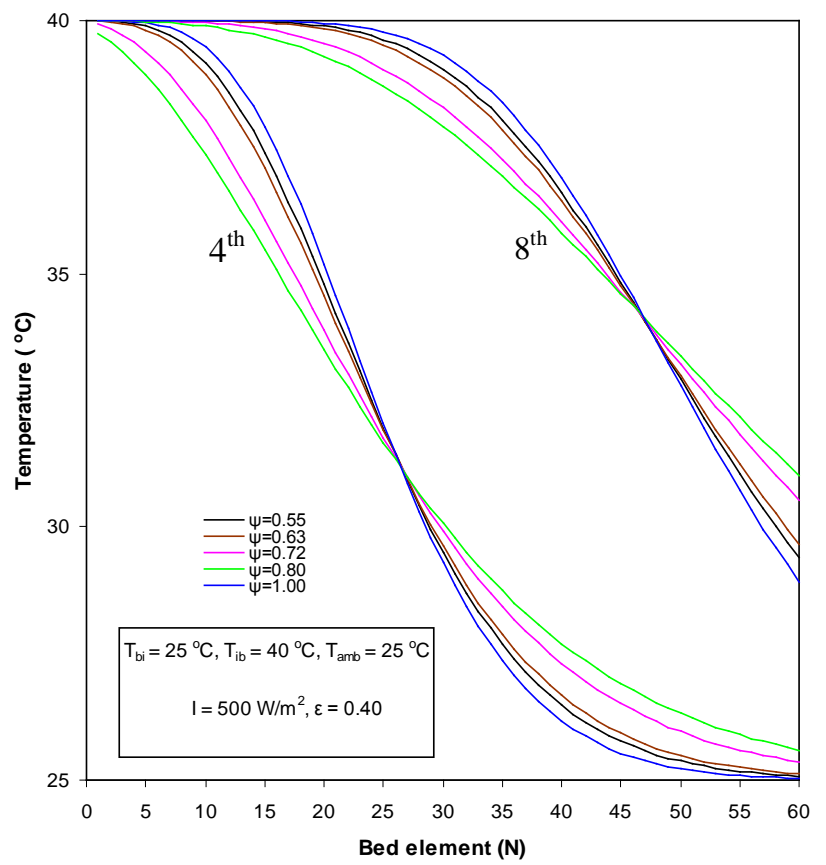

Fig. (1). Temperature distribution in the bed at the end of $4^{\text {th }}$ and $8^{\text {th }}$ hour of charging for material elements of different shapes. 
temperature distribution in the bed for material elements of different shapes. It is observed that bed packed with material elements having sphericity $(\psi)$ of 1.00 is the most stratified i.e. minimum temperature obtained in the lower portion of the bed. It can be observed that the bed with elements yielding maximum heat transfer coefficient leads to higher stratification because more energy transferred in the upper region results into high temperature in the upper region. Air leaves the bed at a temperature almost equal to initial temperature of the bed. Whereas the bed with elements yielding low heat transfer coefficient has relatively lower stratification. The lesser stratified bed results in higher air temperature at the outlet. This temperature influences the flow rate of air in order to yield a constant temperature at the outlet of the collector. The effect of shape of material elements on mean temperature of the bed at the end of charging period is shown in Fig. (2). It is observed that the bed with elements of spherical shape $(\psi=1.00)$ has the maximum mean temperature, while bed with cubes $(\psi=$ 0.80 ) has the minimum mean temperature.

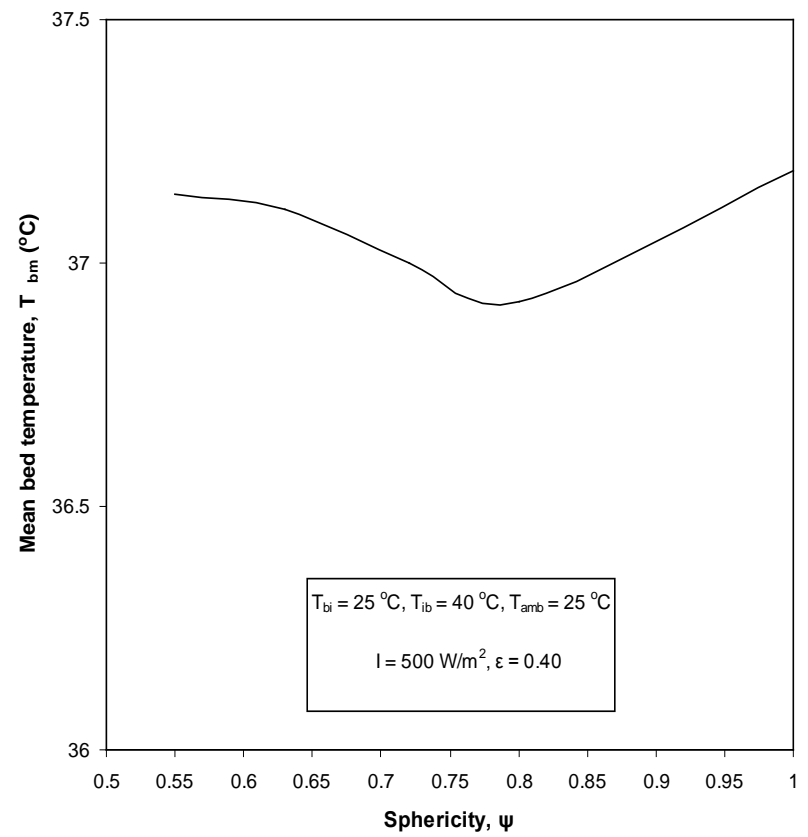

Fig. (2). Effect of sphericity of material elements on mean temperature of the bed at the end of charging.

The effect of void fraction $(\varepsilon)$ on temperature distribution is shown in Fig. (3). It can be observed that the stratification of the bed reduces with increase in void fraction i.e. with increase in void fraction of the bed, temperature increases in lower portion of the bed. The bed at void fraction of 0.31 has the maximum stratification. The bed is least stratified at void fraction of 0.63 . This is due to the fact that with increase in void fraction, heat transfer coefficient between air and solid decreases as has been reported by Singh et al. [2]. As the amount of material packed in the bed reduces with increase of void fraction therefore an early charging of the bed is observed at higher void fractions. At maximum value of void fraction of 0.63 , the bed got fully charged in less than eight hours. Therefore, for void fraction of 0.63 , temperature distribution at the end of eighth hour could not be shown in Fig. (3).

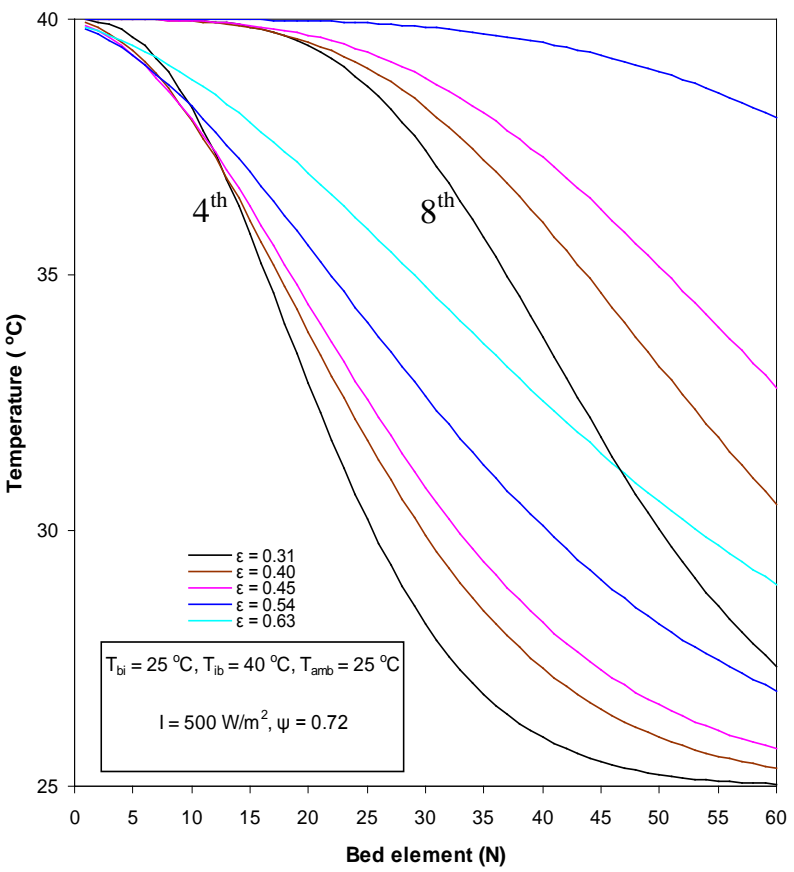

Fig. (3). Temperature distribution in the bed at the end of $4^{\text {th }}$ and $8^{\text {th }}$ hour of charging at different void fractions of the bed.

The effect of void fraction on mean temperature of the bed at the end of charging for eight hours is shown in Fig. (4). It is observed that with increase in void fraction, mean temperature of the bed increases. It resulted due to the fact that with the same amount of energy transfer, the lesser amount of material packed at higher void fraction achieves high temperature.

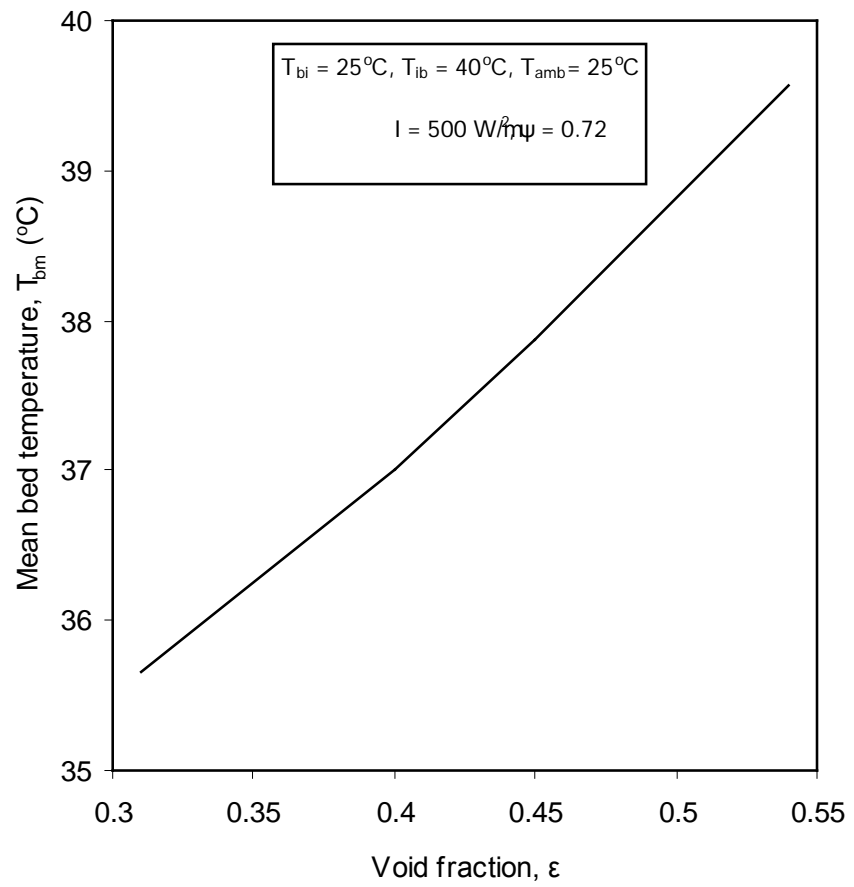

Fig. (4). Effect of void fraction on mean temperature of the bed at the end of charging. 


\subsection{Thermal Energy Stored in the Bed}

The amount of thermal energy stored in the bed using bed elements of different shapes increases with increase in charging time as shown in Fig. (5). During charging, temperature of air at exit of the bed remains constant for short duration and during this period energy stored in the bed also remains same for different shapes of the material elements. With passage of charging time, effect of shape of material elements begins to appear. It is observed that the bed packed with spherical elements $(\psi=1.00)$ has stored maximum amount of thermal energy as compared to the bed packed with non-spherical material as shown in Fig. (6). This is corresponding to the heat transfer coefficient values for different shapes of material elements. The heat transfer coefficient has been found to be maximum for the elements having sphericity of 1.00 and minimum for that of 0.80 as has been reported by Singh et al. [2].

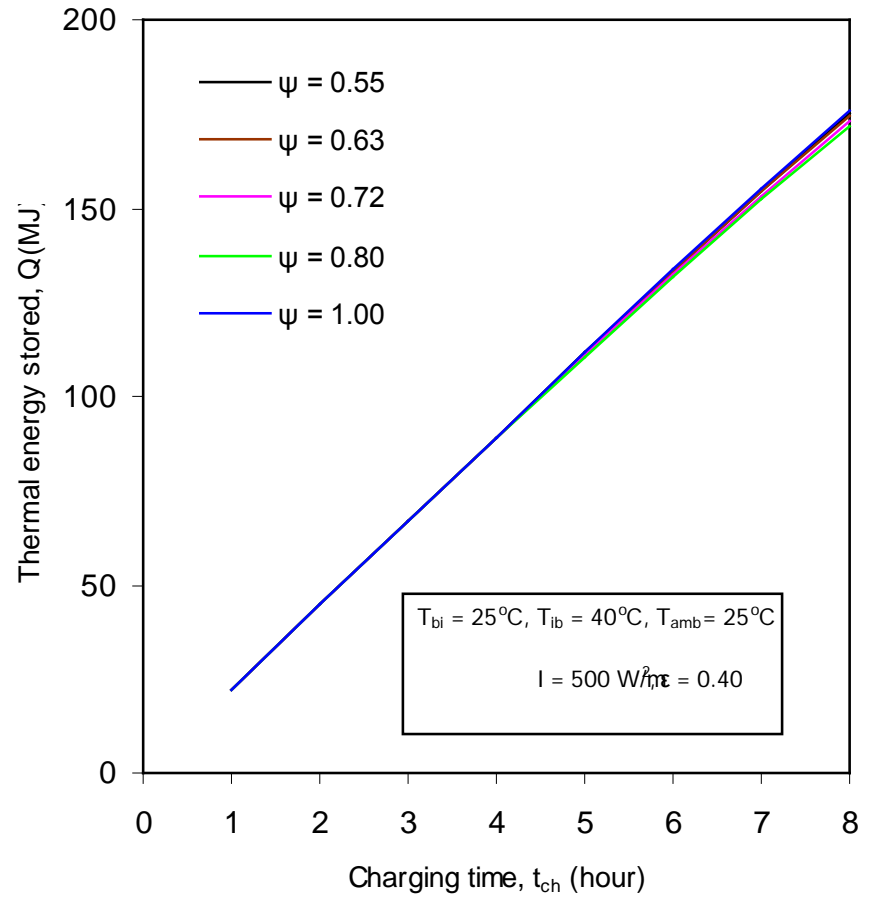

Fig. (5). Variation of thermal energy stored in the bed with charging of bed for different shapes of material elements.

The effect of void fraction on the thermal energy stored in the bed has been shown in Fig. (7). It is indicated that the energy storage decreases with increase in void fraction for the bed packed with elements of a given shape. This also corresponds to the nature of variation of heat transfer coefficient with increase in void fraction. Fig. (8) shows variation of thermal energy stored at the end of charging as function of void fraction.

\subsection{Available Energy Stored in the Bed}

The effect of system parameters on available energy stored in the bed is shown in Figs. (9-12). Fig. (9) shows available energy stored in the bed comprising of bed elements of different shapes packed in the bed at void fraction of 0.40 . The parametric effect of sphericity on available energy stored is similar to the case of thermal energy stored. The bed with spherical elements $(\psi=1.00)$ stored the maximum available energy, however it is found minimum for the bed packed with cubical elements $(\psi=0.80)$ as shown in Fig. (10).

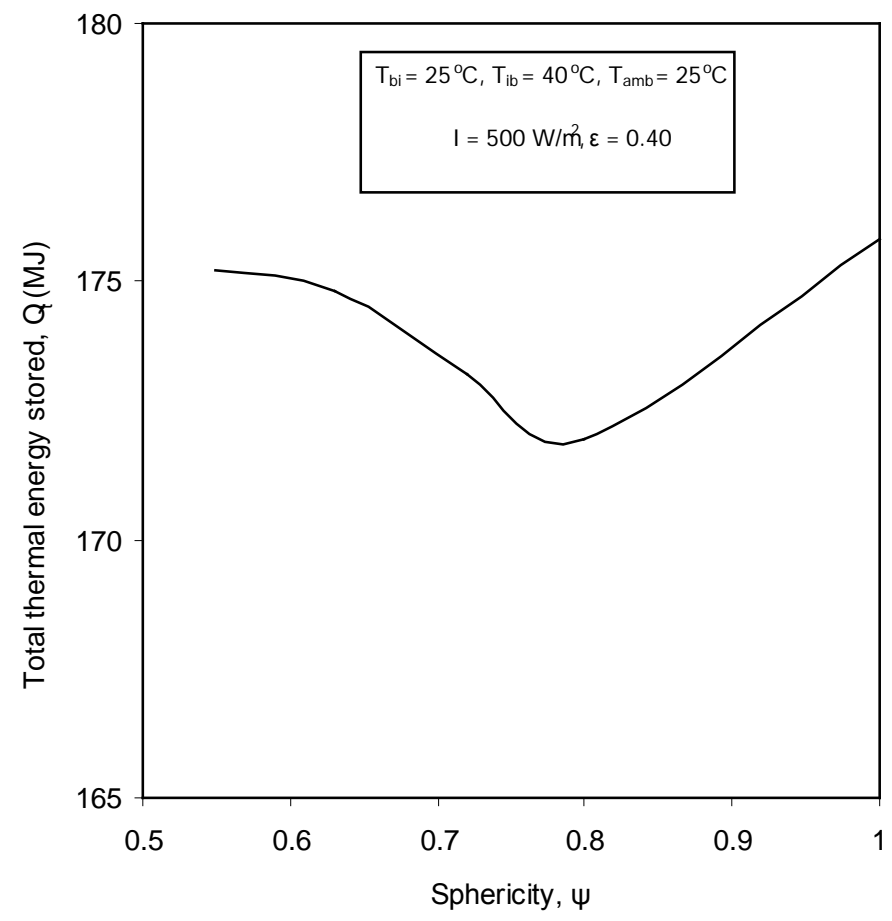

Fig. (6). Effect of sphericity of material elements on total thermal energy stored in the bed during charging period.

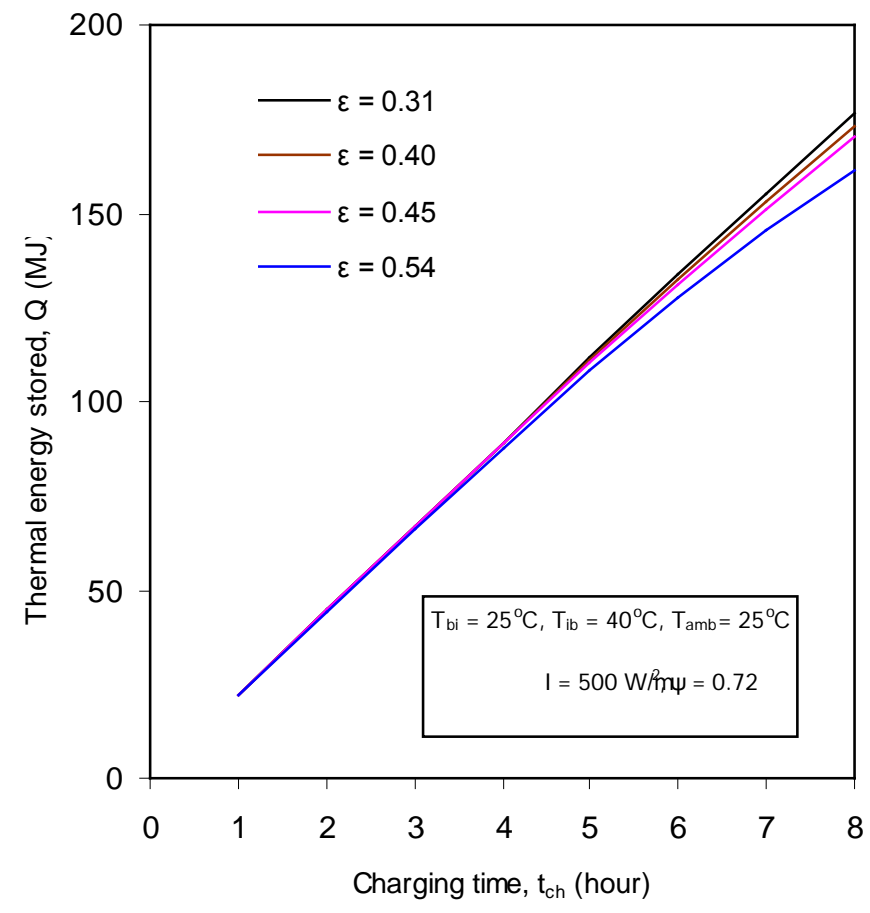

Fig. (7). Variation of thermal energy stored in the bed with charging of bed at different void fractions.

As discussed previously that the bed having elements of spherical shape is the most stratified whereas the least stratified bed has the elements of cubical shape. Even though the energy stored in the bed with elements of different shapes is approximately the same, however an equation of available energy stored used for carrying out mathematical simulation as has been reported in Part-I of 
this paper reveals that the bed with higher stratification should have larger amount of available energy stored. The same observation can be made from Fig. (10).

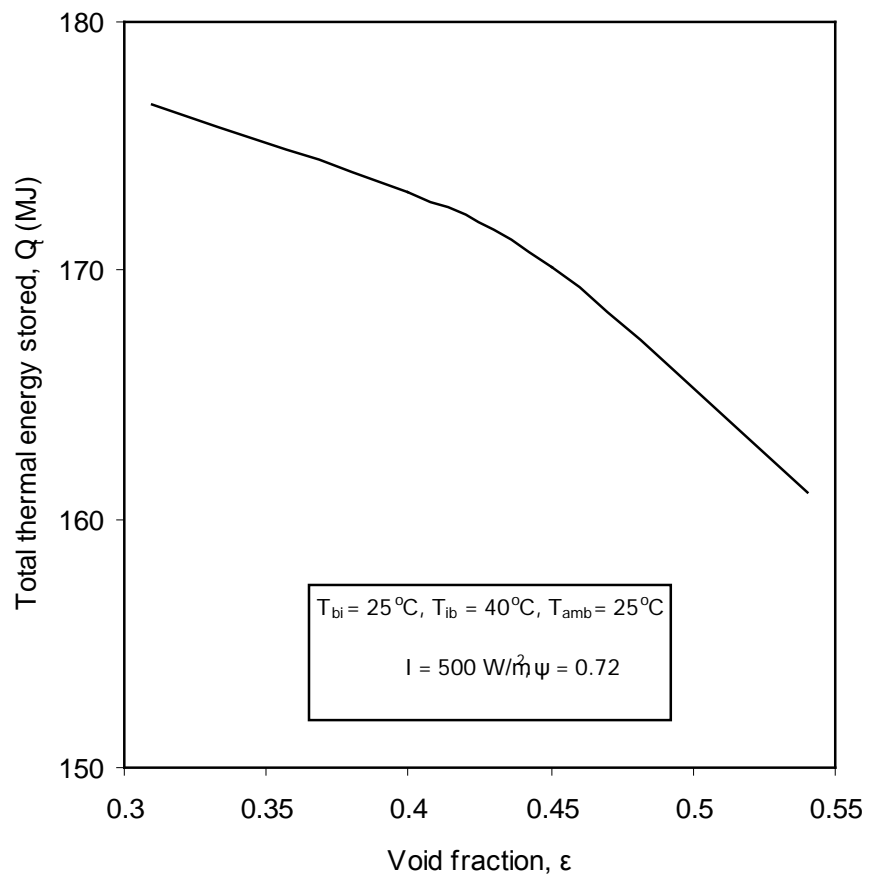

Fig. (8). Effect of void fraction of bed on total thermal energy stored in the bed during charging period.

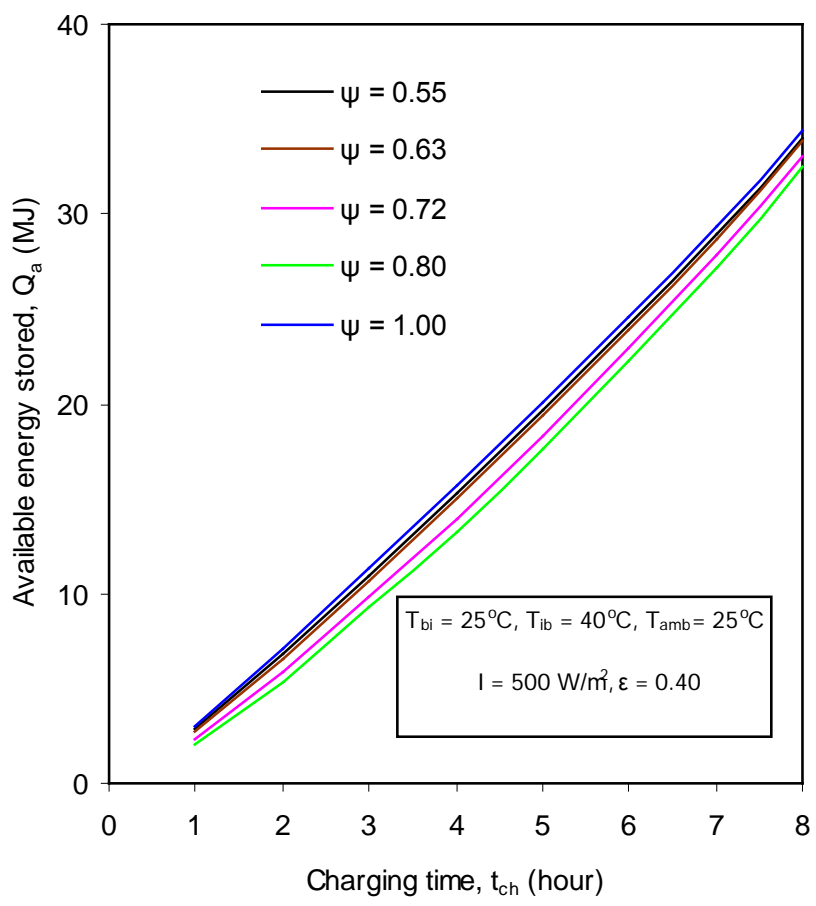

Fig. (9). Effect of charging time on available energy stored in the bed for different shapes of material elements.

An important observation emerged from the comparison of Figs. $(\mathbf{5}, \mathbf{9})$. There is almost no influence of shape on stored thermal energy as observed from Fig. (5) for about half of the charging time. This observation does not appear to be in line with the influence of shape of elements on the temperature profiles (Fig. 1) and available energy (Fig. 9) where the effect of shape is more apparent as compared to that seen in Fig. (5) during this period of charging. It can therefore be concluded that the effect of shape is closely visible on temperature profiles and these temperature variations result into relatively larger influence on available energy as compared to that on thermal energy.

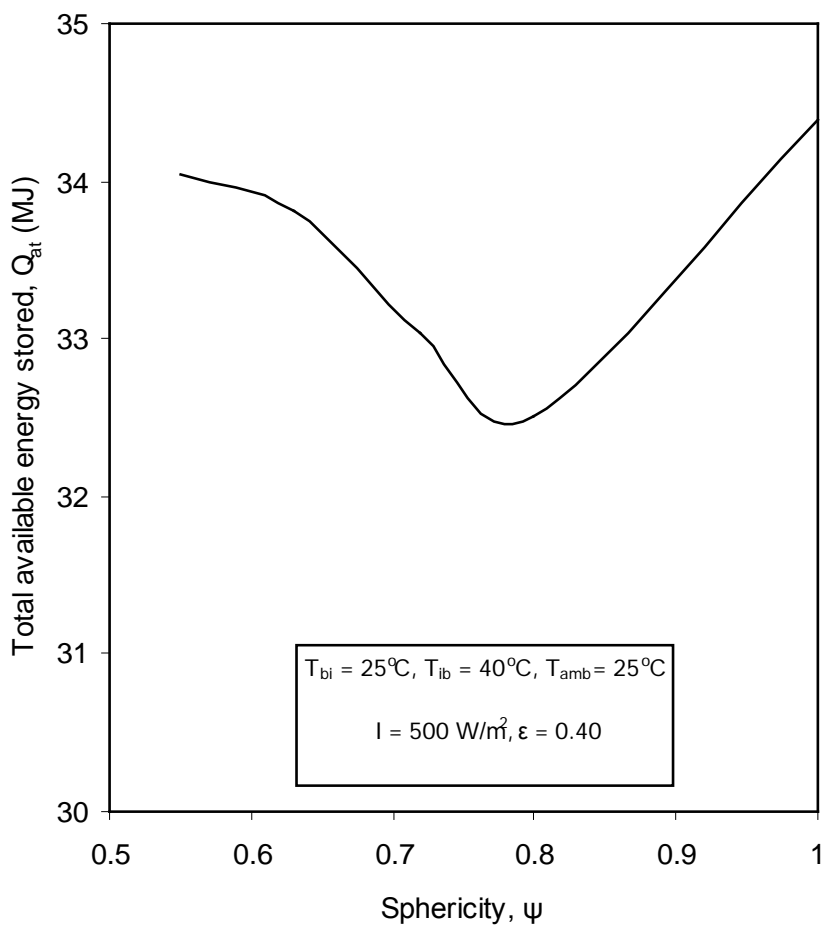

Fig. (10). Effect of shape of material elements on available energy stored in the bed during charging period.

The available energy stored in the bed is also a function of void fraction as can be seen from Fig. (11). It can be observed from Fig. (12) that at the end of charging, available energy stored in the bed is higher for higher void fraction of the bed. A comparison of Figs. $(\mathbf{8}, \mathbf{1 2})$ reveals that the effect of void fraction is totally different in the case of stored thermal energy as compared to stored available energy. The value of stored thermal energy is seen to decline with increasing values of void fraction. The stored available energy monotonously increases with an increase of void fraction. This appears due to the storage of high grade thermal energy at higher values of void fraction under similar operating conditions. It can therefore be concluded that higher void fraction leads to the storage of high grade energy even when the amount of thermal energy stored is relatively smaller. This is an important conclusion, which may help the designer to decide the storage element geometry for optimal conditions.

\section{CONCLUSIONS}

In the present paper an attempt has been made to report and discuss the simulated performance of packed bed solar energy storage system w.r.t. temperature distribution in the bed, thermal energy stored and available energy stored in the bed. It is observed that system parameters play a predominant role to influence heat transfer characteristics of packed bed storage system. 


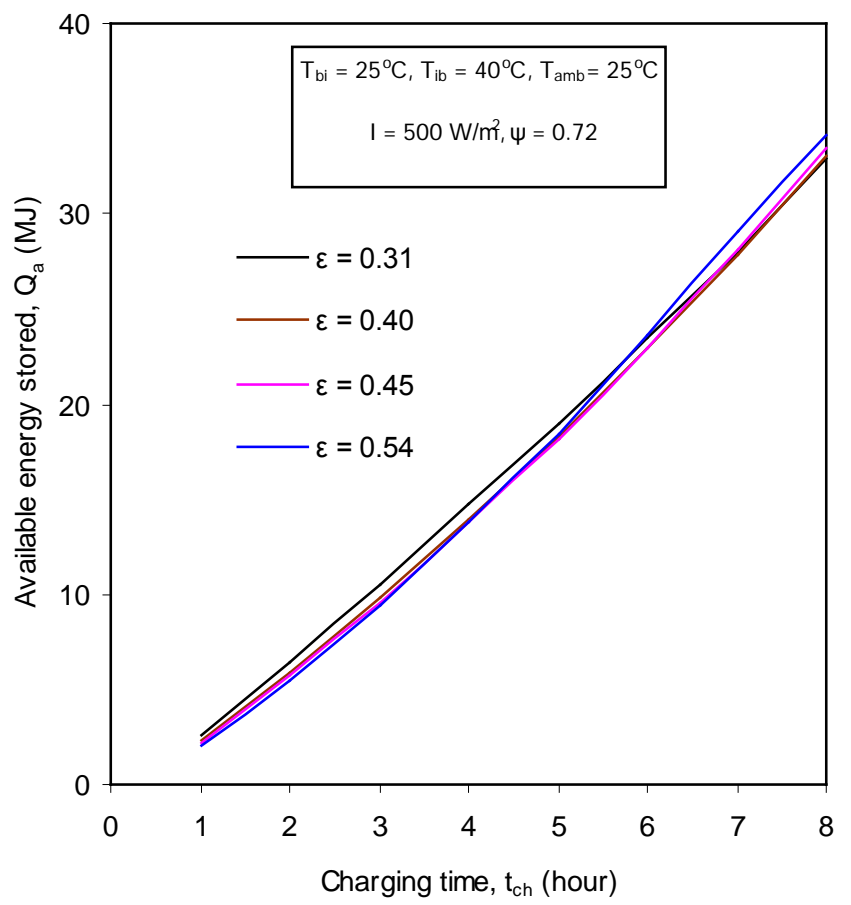

Fig. (11). Variation of available energy stored in the bed with charging time at different void fractions of the bed.

\section{NOMENCLATURE}

$I=$ Insolation $\left(\mathrm{Wm}^{-2}\right)$

$T_{b i} \quad=\quad$ Initial temperature of the bed $\left({ }^{\circ} \mathrm{C}, \mathrm{K}\right)$

$T_{i b}=$ Air temperature at inlet to bed $\left({ }^{\circ} \mathrm{C}, \mathrm{K}\right)$

$T_{a m b}=$ Ambient temperature $\left({ }^{\circ} \mathrm{C}, \mathrm{K}\right)$

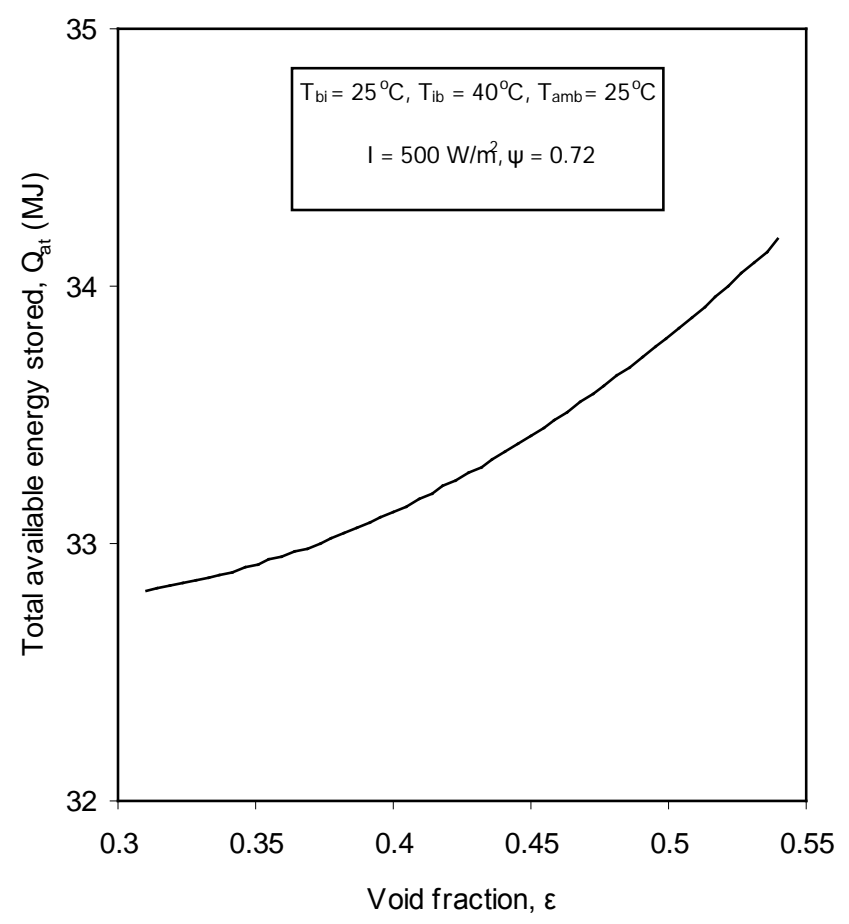

Fig. (12). Effect of void fraction on total available energy stored in the bed at the end of charging.
$\psi \quad=\quad$ Sphericity (dimensionless)
$\varepsilon \quad=\quad$ Void fraction of bed (dimensionless)

\section{REFERENCES}

[1] Sagara, K.; Nakahara, N. Thermal performance and pressure drop of packed beds with large storage materials. Sol. Energy, 1991, 47, 157-163.

[2] Singh, R.; Saini, R.P.; Saini, J.S. Nusselt number and friction factor correlations for packed bed solar energy storage system having large sized elements of different shapes. Sol. Energy, 2006, 80, 760-771. 